\title{
Orlando García Martínez y Michael Zeuske, La sublevación esclava en la goleta Amistad: Ramón Ferrer y las redes de contrabando en el mundo Atlántico, La Habana, Ediciones Unión, 2012, 201 páginas.
}

\author{
Jhandy Castillo Velasco \\ jcastillov@unicartagena.edu.co \\ Senén Puello Suárez \\ spuellos@unicartagena.edu.co*
}

La investigación realizada por los autores sobre la sublevación esclava en la goleta Amistad se enmarca en el contexto de la expansión de la industria azucarera y por ende la demanda de mano de obra esclava para trabajar en las plantaciones cubanas de la primera mitad del siglo XIX, siendo la Isla de Cuba todavía una colonia del imperio español; no obstante, cabe resaltar que para ese tiempo las colonias continentales se habían independizado de España y las Antillas pertenecientes al imperio todavía se encontraban bajo el Antiguo Régimen, razón por la cual la abolición de la esclavitud fue sumamente tardía. García Martínez y Zeuske también realizan una fuerte crítica a la literatura estadounidense y la película de Steven Spielberg alusivas al tema, ya que tanto la una como la otra omiten la importancia del capitán Ferrer, del Caribe, de las Antillas hispanoparlantes y del archipiélago de Cuba, puntos que son fundamentales para el análisis del caso de la sublevación esclava dicha con anterioridad y la misteriosa muerte del capitán de la goleta Amistad. En consecuencia, no debemos pasar por alto que el propósito de los autores en este libro consiste en estudiar a Ramón Ferrer, la tripulación de la goleta Amistad y un cocinero esclavo llamado Celestino, los comerciantes José Ruiz Carrias, Pedro Montes y del papel sumamente importante de las redes de traficantes negreros que proliferaban en los principales puertos de la Isla de Cuba y se conectaban con el mundo Atlántico (p. 10).

* Estudiantes $\mathrm{V}^{\mathrm{o}}$ Semestre Programa de Historia Universidad de Cartagena.

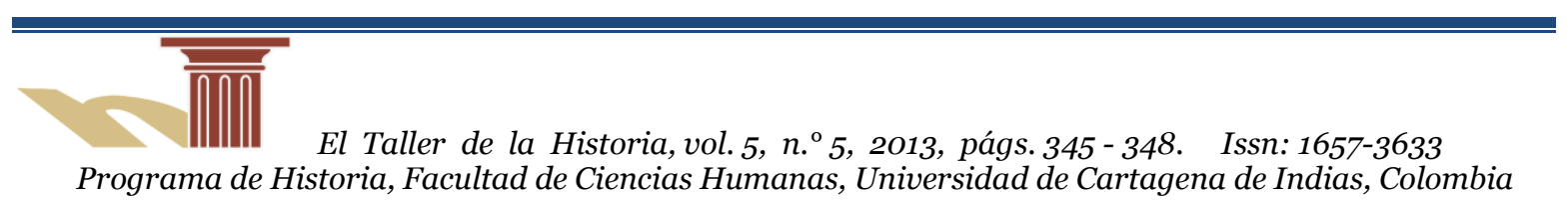


El libro está organizado en seis capítulos. El primero, "La imagen de una sublevación esclava: en busca de los rostros ocultos en la ruta de cabotaje entre La Habana y el sumidero de La Guanaja en Puerto Príncipe", trata sobre la vida de Ramón Ferrer con relación a la expansión de la industria azucarera y el contrabando de esclavos destinados como mano de obra para las plantaciones de caña de azúcar y otras actividades agrícolas. Aquí los autores estudian la inserción de Ramón Ferrer, originario de Ibiza, a la vida económica del puerto de La Habana y como más adelante, junto con su hermano Damián Ferrer y otros capitanes y comerciantes, se integra a una especie de cofradía dedicada al tráfico ilícito de esclavos en varios puertos de Cuba como La Guanaja entre otros. También hace referencia a la construcción de la goleta Amistad y las actividades de contrabando que realizaba estos, siendo capitán de la misma y a la compra del esclavo Celestino, el cual fue testigo y cómplice del capitán Ferrer. Cabe resaltar que los autores resaltan el proceso llamado la atlantización de Cuba como resultado de la migración de esclavos y hombres libres a la isla a causa de la economía azucarera y esclavista.

El segundo capítulo, "El comercio negrero con África: los barcos de Ramón Ferrer en la introducción ilegal de cuerpos humanos", habla de la doble vida de Ramón Ferrer, las estrategias que tanto él como comerciantes provenientes de Cataluña (España) utilizaron para introducir clandestinamente esclavos africanos en la costa norte de Cuba violando el Tratado Internacional para la abolición del tráfico de esclavo que se firmó en 1827. Cambio del nombre de las embarcaciones, utilización de seudónimos por los capitanes, falsificación de documentos, trasbordo de esclavos a otras embarcaciones, complicidad y de las autoridades coloniales españolas y el delito de cohecho, fueron los medios con los cuales Ferrer y sus asociados burlaban la vigilancia de los barcos de guerra británicos. En este capítulo también se hablan sobre la rápida expansión de la industria azucarera junto con su gran demanda de fuerza de trabajo esclava -inversión de capital de cuerpos humanosinfluyó en la inversión de la modernización de la navegación.

El tercer capítulo, "Cautivos africanos, "bultos", esclavos bozales o ladinos en el mundo Atlántico: rebelión y muerte de Ramón Ferrer y Celestino Ferrer en el Amistad", muestra con detalles como se llevaba a cabo las expediciones negreras a la luz de los informes concernientes a la época y en consecuencia como se dio la rebelión de los esclavos con sus respectivas causas. Además explica en qué consistió la carga humana de buques negreros, llamados "bultos", y el trato inhumano dirigido hacia los cautivos por parte de los negreros al marcarlos con hierros - 
denominados Calimbos en lengua bantú- en su cuerpo como propiedad y capital básico de los plantadores; en consecuencia se le otorgaba la nueva identidad a los negros bozales, llamándolos "ladinos", al ser bautizados y al recibir un "nombre cristiano". Los autores también citan relatos de los mismos esclavos referentes al trato de los traficantes negreros hacia éstos, los cuales dan evidencia de la solidaridad de los negros cautivos que más adelante se sublevaron contribuyendo en la muerte de Ramón Ferrer y Celestino.

El cuarto capítulo, "Las huellas, las redes y el dinero en el caso de la goleta Amistad de Cuba", tiene como objetivo señalar las huellas que ha dejado la goleta Amistad dentro de la Isla de Cuba y como éste es fundamental para investigar sobre la redes comerciales ilícitas de mano de obra esclava que eran vendido por un buen precio dentro de barracotes en La Guanaja, Matanzas y La Habana. Otra característica importante que se expone en este capítulo es la capacidad de manejar un bajo perfil en la sociedad evitando toda clase de sospechas de sus actividades ilícitas desarrolladas por Ramón Ferrer a través de su goleta Amistad en la sociedad cubana; estos capitanes tenían respaldo tanto de la autoridades como de los comerciantes, dando muestra de ello las múltiples licencias que generó el capitán Ferrer y que les fueron concebidas para trasladar los "bultos" de negros de un puerto a otro.

El quinto capítulo, "Follow the money: Secretos de la acumulación capitalista, basada en cuerpos humanos- cuba se hace la sociedad esclavista más moderna de occidente alrededor de 1840", hace referencia la acumulación de dinero por diversas actividades en la isla gracias a la modernidad global dentro de la isla lo cual deja visible las inversiones más o menos directas de capital surgido de la trata negrera, en la técnica, ciencia y tecnologías modernas como el ferrocarril, la maquinaria para los grandes ingenios que pretendían modernizar para masificar la producción azucarera en la isla. Los autores también afirman que los créditos otorgados por los comerciantes a los propietarios de ingenios serían fundamentales para invertir en la nueva tecnología, juntamente con la vías de comunicación y la construcción de ferrocarril que fue de gran utilidad tanto para el transporte de personal como del producto de fácil salida en la isla -el azúcar-, llevándolo a los puertos y seguidamente a las goletas de vapor con el fin de comercializar con otros puertos.

El sexto capítulo, "A modo de conclusión: la esclavitud, el atlántico y la modernización tecnológica”, demuestra como los sucesos alrededor de la goleta Amistad, entre otros casos, explican los procesos de acumulación de capital sobre las 
bases de la trata de cuerpos humanos en África y la activa participación de diversos actores sociales del resto del Atlántico. También la vida de Ferrer dio la oportunidad de conocer el contrabando transatlántico, la rápida expansión de la producción azucarera basada en el régimen de trabajo esclavo en las tierras llanas al cultivo cañero llevado a cabo en Cuba y el rastreo del dinero conseguido por este comerciante, las actividades de contrabando y el desarrollo de la infraestructura azucarera.

Ahora bien, en el transcurso del texto los autores utilizan fuentes primarias existentes en archivos de Cuba, Estados Unidos y España, entre los cuales se pueden resaltar algunos como el Archivo Nacional de Cuba, el Archivo Histórico Provincial de Camagüey, el Archivo Histórico de Cienfuegos, el de Matanzas y muchos otros que fueron de gran relevancia para la investigación. Éstas fuentes proporcionaron información necesaria contenidas en cartas, protocolos de compra-venta, testamentos, libros de bautismo y prensa -El Diario de la Habana- que dio la oportunidad de rastrear la vida de Ramón Ferrer y también descubrir más aspectos sobre el comercio ilícito de esclavos. Al tratar una temporalidad tan compleja como lo es el siglo XIX, surgen muchas discusiones sobre los temas relacionados al contrabando, el comercio, la trata de esclavos, la industria azucarera, la modernización, entre otros que enriquecen el trabajo de los autores.

En síntesis, La sublevación esclava en la goleta amistad: Ramón Ferrer y las redes de contrabando en el mundo Atlántico, muestra como el contexto vivido en la sociedad cubana, dio la oportunidad a personas como Ramón Ferrer para conseguir una gran fortuna aprovechando las necesidades existentes en la isla. Gracias a la expansión de la industria azucarera, que requirió mucha mano de obra esclava para el sostén de esta actividad, ésta fuerza de trabajo era muy bien pagada por los propietarios a los traficantes, contribuyendo de esta manera a la acumulación de dinero a los grandes comerciantes y a los capitanes de las goletas. Es importante resaltar el prestigio que tomó el capitán de la goleta Amistad por medio de las donaciones hechas en el pueblo donde residían - poblado de Regla- y por la relación de doble vía que tenía con la sociedad, de día se mostraba como un comerciante honrado y en la noche dedicándose a la actividad de contrabando y trata negrera. 